\title{
Boiling of FC-72 on Surfaces with Open Copper Microchannel
}

\author{
Robert Kaniowski * (D) and Robert Pastuszko \\ Faculty of Mechatronics and Mechanical Engineering, Kielce University of Technology, al. Tysiąclecia P.P. 7., \\ 25-314 Kielce, Poland; tmprp@tu.kielce.pl \\ * Correspondence: kaniowski@tu.kielce.pl
}

check for

updates

Citation: Kaniowski, R.; Pastuszko, R. Boiling of FC-72 on Surfaces with Open Copper Microchannel. Energies 2021, 14, 7283. https://doi.org/ $10.3390 /$ en14217283

Academic Editor: Marco Lorenzini

Received: 7 October 2021

Accepted: 1 November 2021

Published: 3 November 2021

Publisher's Note: MDPI stays neutral with regard to jurisdictional claims in published maps and institutional affiliations.

Copyright: (C) 2021 by the authors. Licensee MDPI, Basel, Switzerland. This article is an open access article distributed under the terms and conditions of the Creative Commons Attribution (CC BY) license (https:// creativecommons.org/licenses/by/ $4.0 /)$.

\begin{abstract}
The paper presents the results of experimental research on pool boiling heat transfer of dielectric liquid FC-72. Measurements were made at atmospheric pressure on open surfaces with microchannels. Heat transfer surfaces, in the form of parallel milled microchannels, were made of copper. The rectangular cross-sectional microchannels were 0.2 to $0.5 \mathrm{~mm}$ deep and 0.2 to $0.4 \mathrm{~mm}$ wide. The surfaces, compared to a smooth flat surface, provided a five-fold increase in the heat transfer coefficient and a two-fold increase in the critical heat flux. The article analyses the influence of the width and height of the microchannel on the heat transfer process. The maximum heat flux was $271.7 \mathrm{~kW} / \mathrm{m}^{2}$, and the highest heat transfer coefficient obtained was $25 \mathrm{~kW} / \mathrm{m}^{2} \mathrm{~K}$. Furthermore, the experimental results were compared with selected correlations for the nucleate pool boiling.
\end{abstract}

Keywords: pool boiling; microchannel; heat transfer coefficient; narrow gap

\section{Introduction}

Heat exchangers, which generate high values of heat flux, are found, for example, in high-power electronic devices and LEDs, nuclear reactors, as well as supercritical steam generators. These applications require the use of highly efficient cooling technology. Due to the boiling of the working fluid, it is possible to stabilize and very effectively remove heat from the devices mentioned above. The search for the most effective extended surfaces of the evaporator depends mainly on the geometric dimensions: width, height, and distance between the microchannels or microfins [1]. This makes it possible to obtain an increase in the heat flux dissipation, depending on the boiling liquid used.

Boiling of dielectric liquids is an area of interest for many researchers. Sajjad et al. [2] have presented an overview of surfaces and techniques used to enhance heat transfer through pool boiling of dielectric liquids and highly wetting liquids. The authors indicated that on a smooth surface, the use of FC-72 allowed them to obtain a critical heat flux (CHF) of about $270 \mathrm{~kW} / \mathrm{m}^{2}$ with a heat transfer coefficient (HTC) greater than $6 \mathrm{~kW} / \mathrm{m}^{2} \mathrm{~K}$. The insufficient thermophysical properties of dielectric liquids force the use of special enhancement methods to increase the CHF and HTC. The authors analyzed the following types of passive cooling methods in particular: coated or additive surfaces, intrinsic or subtractive surfaces, and compound or hybrid surfaces. The use of appropriately selected enhanced surfaces enabled researchers to even obtain a 6-fold increase in porous substrates on the structure (CHF) and a 4.5-fold increase of carbon nanotube coating (HTC) in the boiling of FC-72 in relation to plain smooth surfaces.

Zhang et al. [3] have analyzed the boiling process of FC-72 boiling on surfaces with microfins with a respective width and thickness of $0.03 \mathrm{~mm}$, heights of $0.06-0.12 \mathrm{~mm}$, and pitches of $0.045-0.06 \mathrm{~mm}$. Additionally, various configurations of the fin arrangement were tested. The CHF obtained ranged from 200 to $600 \mathrm{~kW} / \mathrm{m}^{2}$, while the maximum heat transfer coefficients were at the level of $12 \mathrm{~kW} / \mathrm{m}^{2} \mathrm{~K}$. The authors found that changing the microfins' configuration had a more significant effect on HTC than changing the pitch.

$\mathrm{Yu}$ and $\mathrm{Lu}$ [1] researched the pool boiling heat transfer of FC-72 for the array of microfins with a thickness of $1 \mathrm{~mm}$, which were uniformly distributed over an area of 
$10 \times 10 \mathrm{~mm}^{2}$, with a variable microfin height $(0.5-4 \mathrm{~mm})$ and inter-fin space $(0.5-2 \mathrm{~mm})$. The heat transfer coefficients, related to the total extended area, showed a decrease when the space between the microfins was smaller and their height was greater. The HTC values obtained reached $10 \mathrm{~kW} / \mathrm{m}^{2} \mathrm{~K}$, whereas the CHF reached the level of $1000 \mathrm{~kW} / \mathrm{m}^{2}$. The influence of the diameter of copper nanowires in the range of 35-200 $\mathrm{nm}$ on the intensification of heat transfer at the boiling of FC-72 was investigated by Kumar et al. [4]. An increase of approximately $45 \%$ in CHF was achieved compared to a plain smooth surface, reaching about $225 \mathrm{~kW} / \mathrm{m}^{2}$, and a $185 \%$ gain in HTC was achieved, which exceeded $12 \mathrm{~kW} / \mathrm{m}^{2} \mathrm{~K}$. Kong et al. [5] proposed a bistructured surface in the form of a $0.03 \mathrm{~mm}$ thick and $0.06 \mathrm{~mm}$ high microfin, forming fins that are 0.7 and $1.4 \mathrm{~mm}$ thick, arranged in four configurations. The structural surfaces designed in this way allowed to achieve CHF values that exceeded $500 \mathrm{~kW} / \mathrm{m}^{2}$ for liquid subcooling $35 \mathrm{~K}$. Hao et al. [6] used a shape memory alloy to change the geometry and shape of a surface with fins of $4 \mathrm{~mm}$ height and $0.5 \times 2 \mathrm{~mm}^{2}$ cross-section. With small heat flux, the fins deformed and formed closed tunnels, whereas with larger heat flux, they straightened, increasing the efficiency of vapor removal. The authors called this mechanism "adaptive control of boiling heat transfer". These opened channels made it possible to increase the CHF for FC-72 from approximately 150 to $250 \mathrm{~kW} / \mathrm{m}^{2}$ and to increase HTC by approximately two times (to $13.5 \mathrm{~kW} / \mathrm{m}^{2} \mathrm{~K}$ ).

The boiling of FC-72 was also investigated by Ho et al. [7]. They used surfaces with microcavity with a depth of $0.2 \mathrm{~mm}$ and microfins with a height of $0.4-0.55 \mathrm{~mm}$ of various configurations, obtained using the selective laser melting technique. For microfins, the HTC increased by up to $70 \%$ and the CHF increased by $76 \%$, with the highest heat transfer coefficient reaching $12.7 \mathrm{~kW} / \mathrm{m}^{2} \mathrm{~K}$. Furberg and Palm [8] used advanced dendritic and microporous surface technology: copper nanoparticles were joined to the porous structure by electrodeposition. For boiling FC-72, a more than four-fold increase in HTC was obtained, exceeding $40 \mathrm{~kW} / \mathrm{m}^{2} \mathrm{~K}$.

The boiling of the working fluid under consideration was also analyzed in relation to heat exchangers with forced flow through micro- and minichannels with different spatial orientations. Piasecka and Strak [9] obtained HTC values at the level of up to $100 \mathrm{~kW} / \mathrm{m}^{2} \mathrm{~K}$ for vertical minichannels (1.7 $\mathrm{mm}$ deep, $16 \mathrm{~mm}$ wide) with an enhanced surface in the form of microcavities. Strąk and Piasecka [10] conducted research on subcooled flow boiling in structured minichannels (laser surface texturing or electromachining) at different slopes. By analyzing the given Nusselt numbers, for the hydraulic diameter of the minichannel of $3 \mathrm{~mm}$, HTCs were obtained in the range $0.86-5.8 \mathrm{~W} / \mathrm{m}^{2} \mathrm{~K}$. For saturated flow boiling in a $1.7 \mathrm{~mm}$ deep minichannel with an enhanced surface, Piasecka et al. [11] obtained an HTC exceeding $60 \mathrm{~kW} / \mathrm{m}^{2} \mathrm{~K}$.

The available literature lacks experimental data obtained with the use of FC-72 boiling on surfaces with microchannels. There is also no presentation of simple correlations that would make it possible to estimate the heat transfer coefficient for this type of surface. This article is an attempt to supplement and broaden the knowledge of the nucleate pool boiling of dielectric fluid. The purpose of this study was to analyze the results of FC-72 pool boiling tests on a surface with microchannels with a width of $0.2-0.4 \mathrm{~mm}$ and depths of $0.2-0.5 \mathrm{~mm}$ and to compare the heat transfer coefficients and the maximum heat fluxes with the data in the available literature. An attempt was made to adjust the existing correlations for pool boiling on a plain surface to that of a boiling on the analyzed extended surfaces.

\section{Experimental Setup}

The test stand shown in Figure 1, which is a modification of the stand described in $[12,13]$, made it possible to measure the parameters necessary to analyze the heat transfer process. The temperatures of the copper block installed in the main module were measured, and the superheat of the test surface, the heat flux, and the heat transfer coefficients were determined. Based on the collected data, the boiling curves were plotted. K-type thermocouples with a diameter of $0.5 \mathrm{~mm}$ were used to measure the temperature in the upper part of the copper block and under the tested specimen. The thermocouples were 
calibrated with an Altek 422 calibrator prior to measurements. Temperature measurements were recorded every $15 \mathrm{~min}$ by a FLUKE Hydra Series II data acquisition station. This time was sufficient for the test stand used and allowed for the temperatures to stabilize and the nucleation centers to be activated. The one-dimensional heat conduction in the copper block was checked by defining the coefficient of determination $R^{2}$. In the study, the linearity of the temperature values along the axis of the heating cylinder (copper block) was determined [14], obtaining a coefficient of determination greater than 0.99 . $R^{2}$ belongs to the range $<0,1>$. This parameter was used to check the correct mounting of the specimen and thermocouples on the heating cylinder. If the value of the coefficient of determination was greater than 0.98 , it was assumed that the specimen was soldered to the copper block correctly and there was no heat flow in the direction perpendicular to the copper block axis. A value of $R^{2}<0.98$ indicates a higher thermal resistance in the solder layer and the experimental measurements are too error prone.

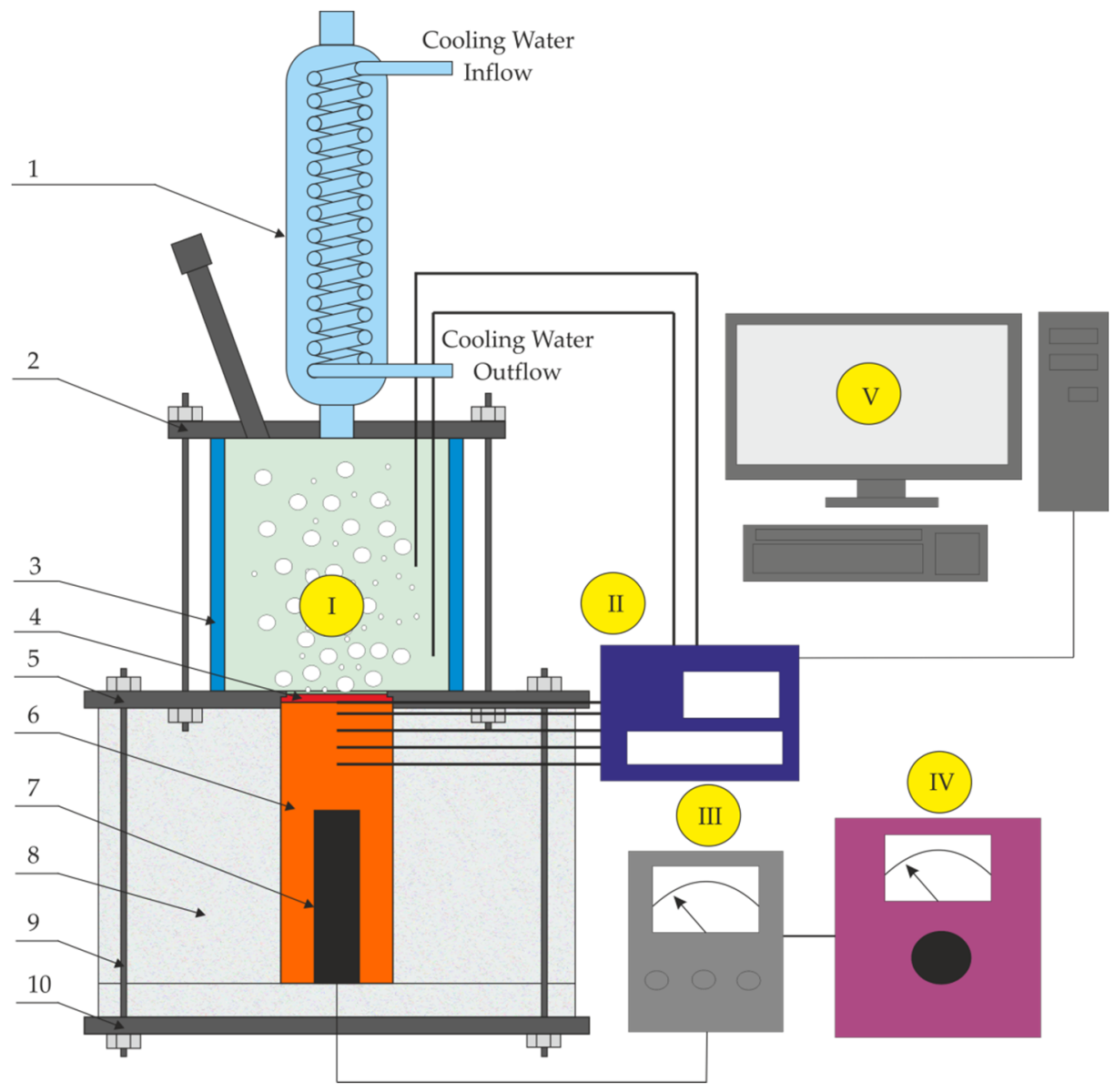

Figure 1. Pool boiling measurement stand. I-main module, II-data logger, III-wattmeter, IVautotransformer, and V-PC; 1-condenser, 2-top flange, 3-glass vessel, 4-test surface, 5-Teflon lid, 6-copper block, 7-cartridge heater, 8-insulation, 9-threaded rod, and 10-Teflon base.

The tests were carried out in a large volume of working fluid, that is, the liquid level above the specimen surface exceeded $50 \mathrm{~mm}$. Before starting the measurements, the liquid was degassed in the standby, bringing it to the boiling point and keeping this process for $15 \mathrm{~min}$. The research was carried out with an increase in the heat flux until the boiling crisis ( $\mathrm{CHF}$ - critical heat flux) was reached. The experiment was performed at atmospheric pressure.

During the tests, a highly volatile FC-72 dielectric liquid with a low saturation temperature was used. The thermophysical properties of this liquid are given in Table 1 based on [4]. To properly perform the tests, the experimental stand had to meet high-tightness 
requirements. For this purpose, the glass vessel with a Teflon lid and top flange was sealed with high-temperature silicone.

Table 1. Thermophysical properties of FC-72.

\begin{tabular}{cc}
\hline Parameters at 1013.25 hPa & FC-72 \\
\hline $\mathrm{T}_{\text {sat }}, \mathrm{K}$ & 329.6 \\
$\rho_{1}, \mathrm{~kg} / \mathrm{m}^{3}$ & 1602 \\
$\rho_{\mathrm{v}}, \mathrm{kg} / \mathrm{m}^{3}$ & 13.24 \\
$\mathrm{i}_{\mathrm{lv}}, \mathrm{J} / \mathrm{kg}$ & 94900 \\
$\lambda_{1}, \mathrm{~W} / \mathrm{mK}$ & 0.0540 \\
$\sigma_{1}, \mathrm{~N} / \mathrm{m}$ & 0.0081 \\
$v_{1}, \mathrm{~m}^{2} / \mathrm{s}$ & 0.00000027 \\
$\mu_{1}, \mathrm{Pas}$ & 0.0004325 \\
$\mathrm{c}_{\mathrm{p}}, \mathrm{J} / \mathrm{kgK}$ & 1101 \\
$\mathrm{Pr}$ & 8.819 \\
\hline
\end{tabular}

The capillary length $\left(\mathrm{L}_{\mathrm{cap}}=0.72 \mathrm{~mm}\right)$ was determined on the basis of the following formula:

$$
\mathrm{L}_{\text {cap }}=\sqrt{\frac{\sigma}{\mathrm{g}\left(\rho_{1}-\rho_{\mathrm{v}}\right)}}
$$

and the Prandtl number is defined as:

$$
\operatorname{Pr}=\frac{c_{p} \mu_{1}}{\lambda_{1}}
$$

The specimens with cut microchannels were made of copper with a thermal conductivity coefficient $\lambda_{\mathrm{Cu}}=380 \mathrm{~W} /(\mathrm{mK})$ using a miller and an end milling cutter with a width of $0.2,0.3$, and $0.4 \mathrm{~mm}$ (Figure 2). The active area of the specimen was a $\times \mathrm{w}_{\mathrm{s}}$ and was equal to $27 \times 27 \mathrm{~mm}^{2}$ (Figure 3). The heating cylinder was made of the same material as the specimens. Pure, lead-free tin with a thermal conductivity of $\lambda_{\mathrm{Sn}}=66.5 \mathrm{~W} / \mathrm{mK}$ was used to connect the specimen and the heating cylinder. The thickness of the tin layer was about $0.1 \mathrm{~mm}$. Figure 3 shows the arrangement of the thermocouples and the geometric dimensions necessary for the calculation of the heat flux and the heat transfer coefficient.

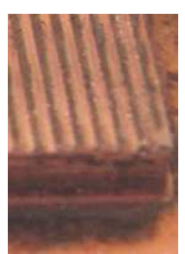

(a)

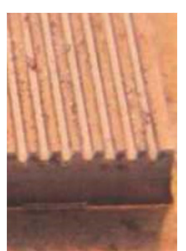

(b)

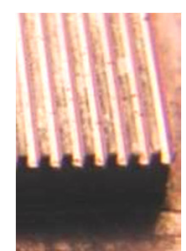

(c)

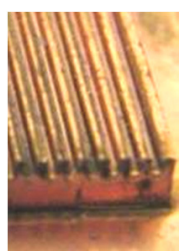

(d)

Figure 2. View of the specimens, with the specimen's code: width-depth-pitch (mm). (a) MC-0.3-0.20.6. (b) MC-0.3-0.3-0.6. (c) MC-0.3-0.4-0.6. (d) MC-0.3-0.5-0.6. Designations according to Table 2.

The heat transfer coefficient between the surface with microchannels and boiling FC-72 was defined according to Newton's law:

$$
\alpha=\frac{\mathrm{q}}{\Delta \mathrm{T}}
$$

The heating cylinder was covered with a thick insulating layer; hence, the onedimensional Fourier equation was used to calculate the heat flux:

$$
\mathrm{q}=\lambda_{\mathrm{Cu}} \frac{\mathrm{T}_{\mathrm{T} 8}-\mathrm{T}_{\mathrm{T}}}{\delta_{\mathrm{T} 8-\mathrm{T} 5}} \cdot \frac{\pi \mathrm{d}_{\mathrm{cyl}}^{2}}{4 \mathrm{a}^{2}}
$$



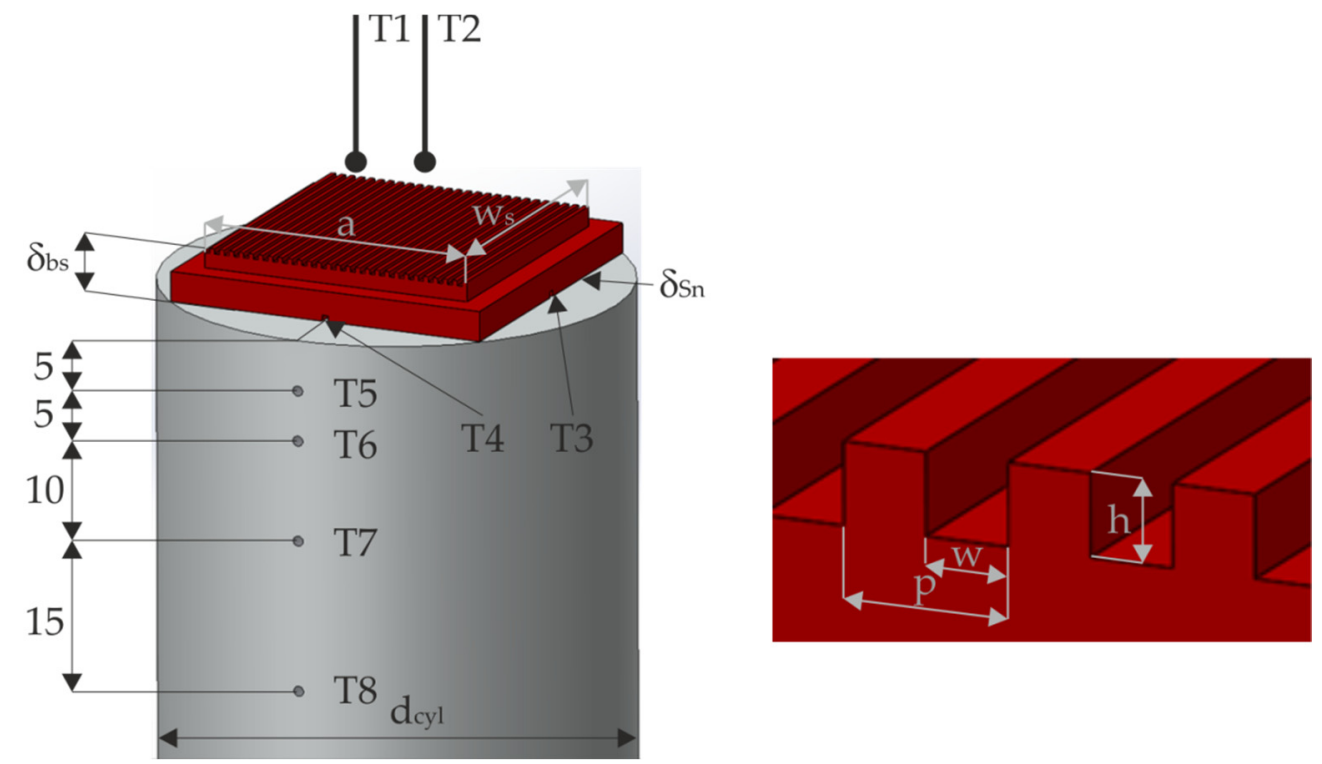

Figure 3. Arrangement of the thermocouples and magnification of the specimen with microchannel dimension.

The temperature difference between the surface with microchannels and the boiling liquid (superheat) related to the bottom of the microchannels (i.e., the base of the microfins) was defined in accordance with Figure 3:

$$
\Delta \mathrm{T}=\frac{\mathrm{T}_{\mathrm{T} 3}+\mathrm{T}_{\mathrm{T} 4}}{2}-\mathrm{q}\left(\frac{\delta_{\mathrm{bs}}}{\lambda_{\mathrm{Cu}}}+\frac{\delta_{\mathrm{Sn}}}{\lambda_{\mathrm{Sn}}}\right)-\frac{\mathrm{T}_{\mathrm{T} 1}+\mathrm{T}_{\mathrm{T} 2}}{2}
$$

The surface extension coefficient (enhancement factor) was defined as the ratio of the extended surface area to the base surface area:

$$
\varphi=\frac{\mathrm{A}_{\mathrm{ext}}}{\mathrm{A}_{\mathrm{bs}}}=\frac{(2 \mathrm{~h}+\mathrm{p}) \mathrm{w}_{\mathrm{s}}}{\mathrm{pw}_{\mathrm{s}}}=\frac{2 \mathrm{~h}+\mathrm{p}}{\mathrm{p}}
$$

where $\mathrm{p}=2 \mathrm{w}$ and the efficiency $\varphi$ can be calculated as $\varphi=\mathrm{h} / \mathrm{w}+1$.

In the analysis of the experimental results, the efficiency of the microfin was taken into consideration, defined as the ratio of the heat transfer through the microfin at the actual temperature distribution to the amount of heat that would be transferred through the microfin at a constant temperature along the fin height [15]:

$$
\eta=\frac{\tanh m\left(h+\frac{p-w}{2}\right)}{m\left(h+\frac{p-w}{2}\right)}
$$

where the microfin parameter $\mathrm{m}$ can be calculated from the following equation:

$$
\mathrm{m}=\sqrt{2 \frac{\alpha\left(p-w+w_{s}\right)}{\lambda_{C u}(p-w) w_{s}}}
$$

The fin efficiency can be approximated from the following relation:

$$
\varepsilon \approx \varphi \eta
$$


For microchannels, the Bond number is defined as the square of the ratio of hydraulic diameter to capillary length, $B o=\left(d_{h} / L_{c a p}\right)^{2}$, which can also be defined as:

$$
\text { Bo }=\left(\frac{2 w h}{w+h}\right)^{2} \frac{g\left(\rho_{1}-\rho_{v}\right)}{\sigma}
$$

Table 2 shows the geometrical parameters of the specimens tested and the remaining values analyzed in Section 3.

Table 2. Surface codes and specifications.

\begin{tabular}{|c|c|c|c|c|c|c|c|c|c|c|}
\hline Specimen Code & $\mathbf{w}, \mathbf{m m}$ & $\mathrm{h}, \mathrm{mm}$ & $\mathrm{p}, \mathrm{mm}$ & $\varphi$ & $\varepsilon_{\mathrm{CHF}}$ & $\mathcal{E}_{\text {HTCmax }}$ & $\mathrm{d}_{\mathrm{h}} / \mathrm{L}_{\text {cap }}$ & Bo & $\mathrm{Bo}^{0.5} \varepsilon_{\text {HTCmax }}$ & $\alpha / \alpha_{\text {smooth }}$ \\
\hline MC-0.2-0.2-0.4 & 0.20 & 0.20 & 0.40 & 2.00 & 1.96 & 1.95 & 0.278 & 0.077 & 0.542 & 3.3 \\
\hline MC-0.2-0.3-0.4 & 0.20 & 0.30 & 0.40 & 2.50 & 2.41 & 2.40 & 0.333 & 0.111 & 0.800 & 3.8 \\
\hline MC-0.2-0.4-0.4 & 0.20 & 0.40 & 0.40 & 3.00 & 2.82 & 2.79 & 0.370 & 0.137 & 1.034 & 4.8 \\
\hline MC-0.2-0.5-0.4 & 0.20 & 0.50 & 0.40 & 3.50 & 3.22 & 3.18 & 0.397 & 0.157 & 1.261 & 4.8 \\
\hline MC-0.3-0.2-0.6 & 0.30 & 0.20 & 0.60 & 1.67 & 1.66 & 1.65 & 0.333 & 0.111 & 0.551 & 2.7 \\
\hline MC-0.3-0.3-0.6 & 0.30 & 0.30 & 0.60 & 2.00 & 1.96 & 1.95 & 0.417 & 0.173 & 0.812 & 4.3 \\
\hline MC-0.3-0.4-0.6 & 0.30 & 0.40 & 0.60 & 2.33 & 2.29 & 2.27 & 0.476 & 0.226 & 1.078 & 3.2 \\
\hline MC-0.3-0.5-0.6 & 0.30 & 0.50 & 0.60 & 2.67 & 2.47 & 2.44 & 0.521 & 0.271 & 1.271 & 5.1 \\
\hline MC-0.4-0.2-0.8 & 0.40 & 0.20 & 0.80 & 1.50 & 1.46 & 1.46 & 0.370 & 0.137 & 0.540 & 3.6 \\
\hline MC-0.4-0.3-0.8 & 0.40 & 0.30 & 0.80 & 1.75 & 1.69 & 1.68 & 0.476 & 0.226 & 0.798 & 5.2 \\
\hline MC-0.4-0.4-0.8 & 0.40 & 0.40 & 0.80 & 2.00 & 1.93 & 1.92 & 0.556 & 0.308 & 1.066 & 3.0 \\
\hline MC-0.4-0.5-0.8 & 0.40 & 0.50 & 0.80 & 2.25 & 2.11 & 2.09 & 0.617 & 0.380 & 1.291 & 4.2 \\
\hline
\end{tabular}

The heat flux and the heat transfer coefficient uncertainty determination method were presented in a previous study [16]. The relative error of heat flux for the range of 6.1 to $271.7 \mathrm{~kW} / \mathrm{m}^{2}$ decreased in the range of $91 \%$ to $3.1 \%$, as seen in Figure 4 . A similar trend is shown in Figure 5, where the relative error of the heat transfer coefficient decreased in the range of 1.3 to $25.0 \mathrm{~kW} / \mathrm{m}^{2} \mathrm{~K}$ and the values fell between $91 \%$ and $4.1 \%$.

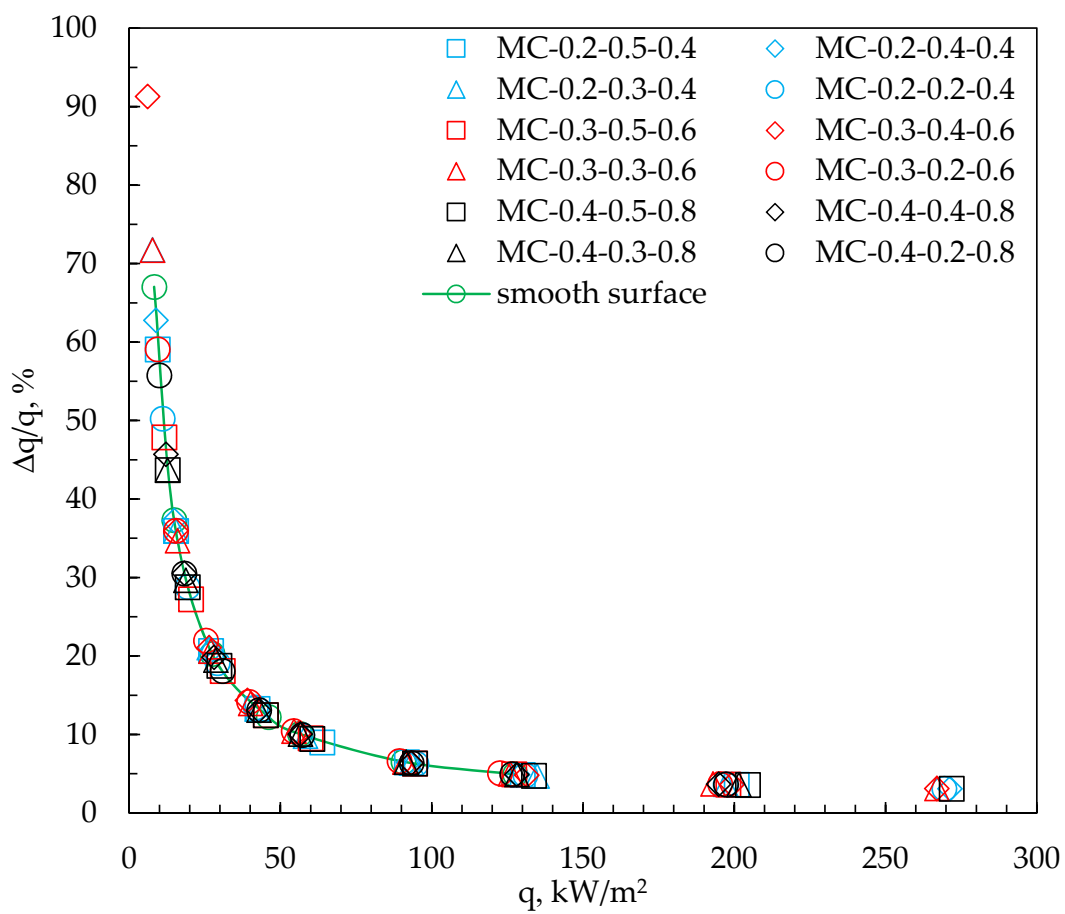

Figure 4. Relative uncertainty at different heat fluxes. 


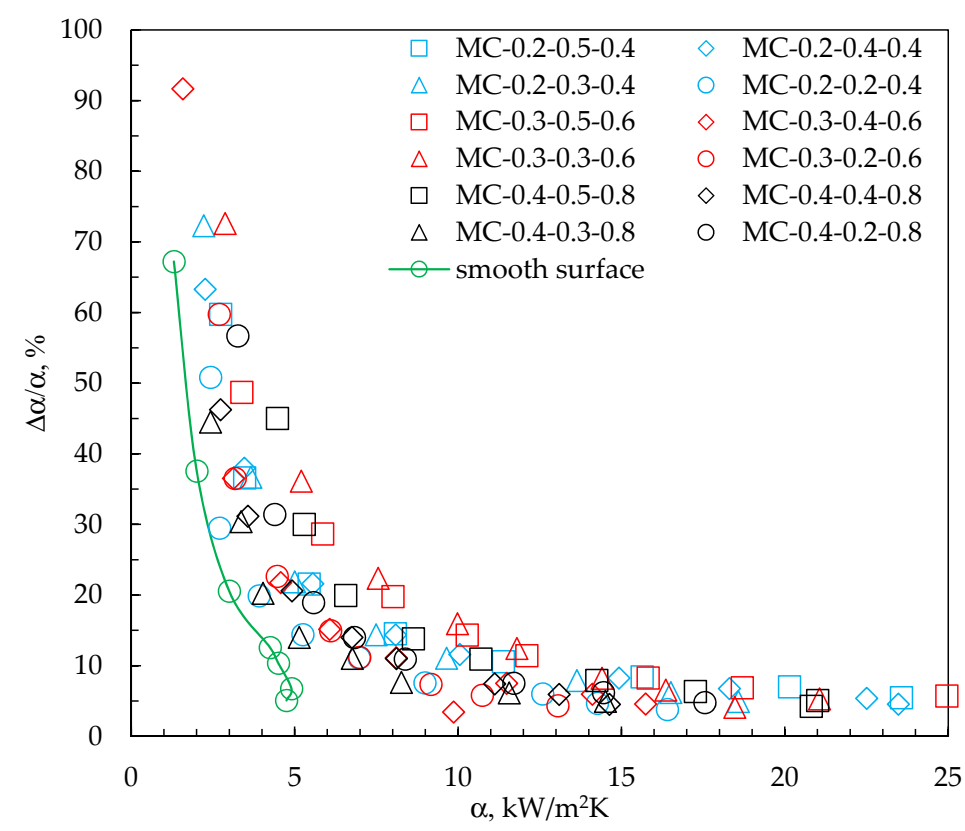

Figure 5. Relative uncertainty at different heat transfer coefficients.

\section{Results and Discussion}

Experimental investigations were carried out for boiling FC-72, at atmospheric pressure, on a smooth plain surface and surfaces with machined microchannels. The influence of the depth and width of the microchannels on the heat transfer performance was analyzed. The best results were obtained for surfaces with microchannels $0.3 \mathrm{~mm}$ wide and $0.5 \mathrm{~mm}$ deep (MC-0.3-0.5-0.6). The heat transfer coefficient reached the value of $24.95 \mathrm{~kW} / \mathrm{m}^{2} \mathrm{~K}$ with a heat flux of $198 \mathrm{~kW} / \mathrm{m}^{2}$ at superheat $\Delta \mathrm{T} \approx 7.9 \mathrm{~K}$, as shown in Figures 6 and 7 . An over five-fold increase in the HTC was obtained in relation to the smooth surface specimen, as shown in Figure 7, and at relatively small heat fluxes of 20 to $60 \mathrm{~kW} / \mathrm{m}^{2}$, the heat transfer coefficients were three times greater than for the smooth reference surface. This is related to the increase in the heat transfer surface, i.e., the increase in efficiency $\varphi$ and effectiveness $\varepsilon_{\mathrm{CHF}}$.

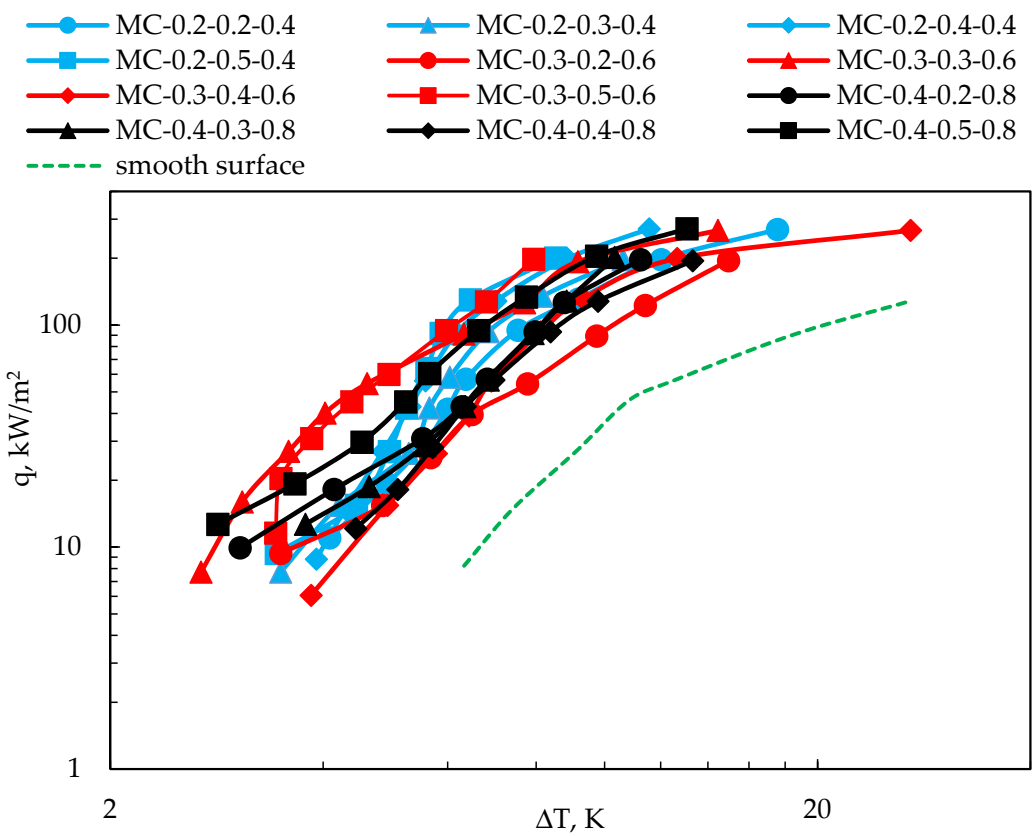

Figure 6. Boiling curves for FC-72: heat flux versus superheat. 


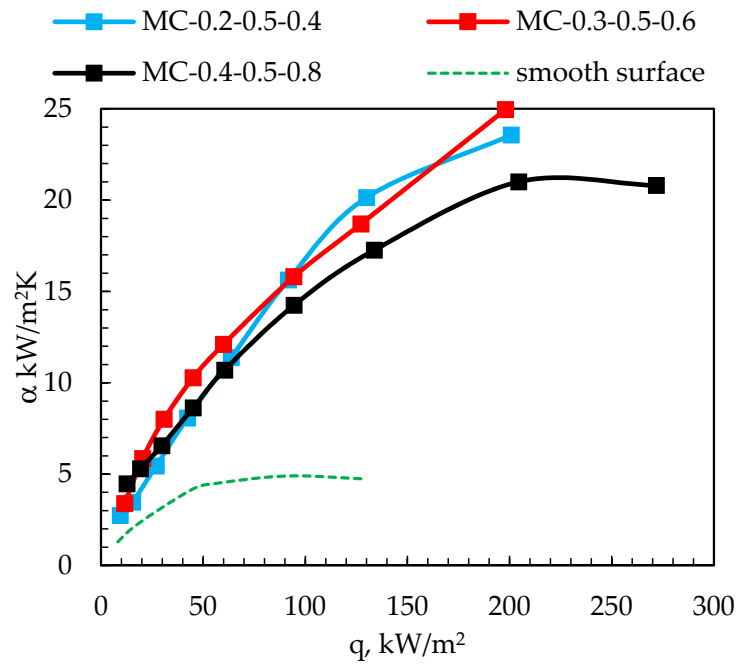

(a)

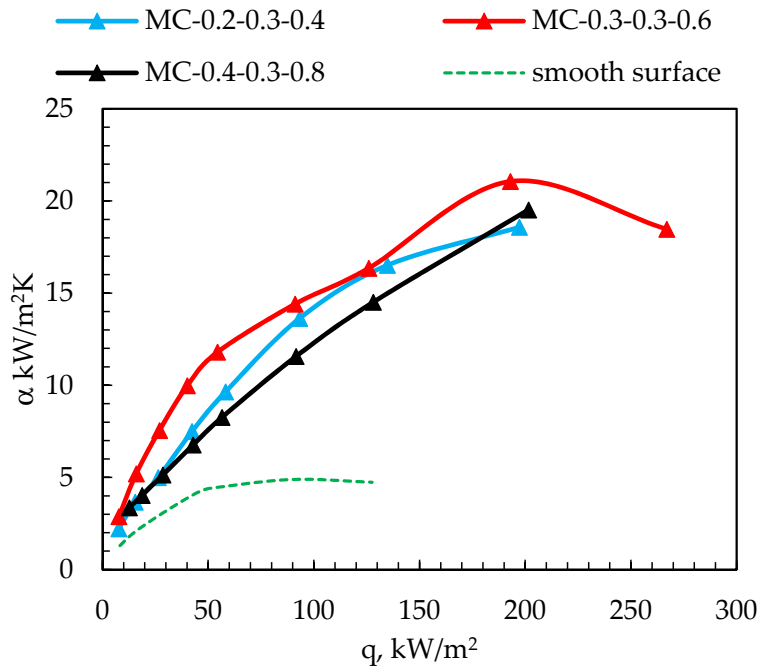

(c)

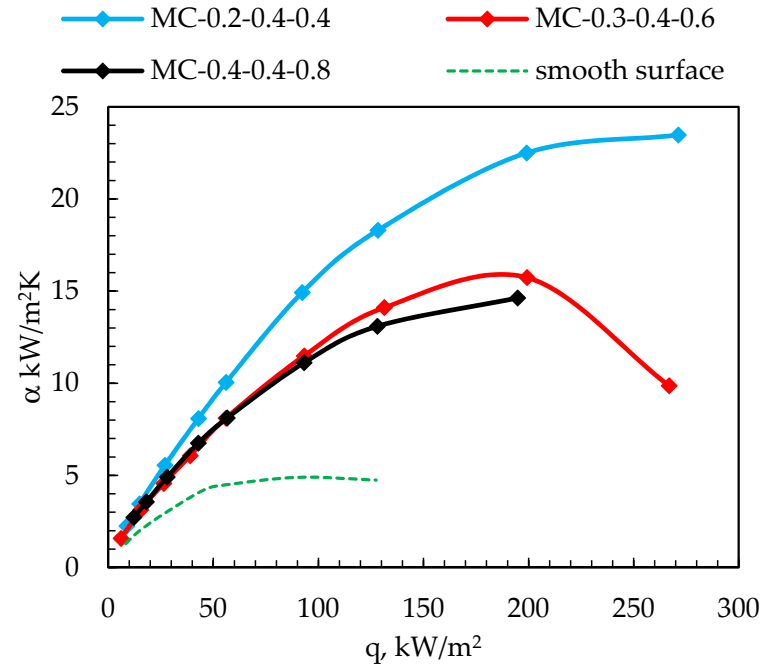

(b)

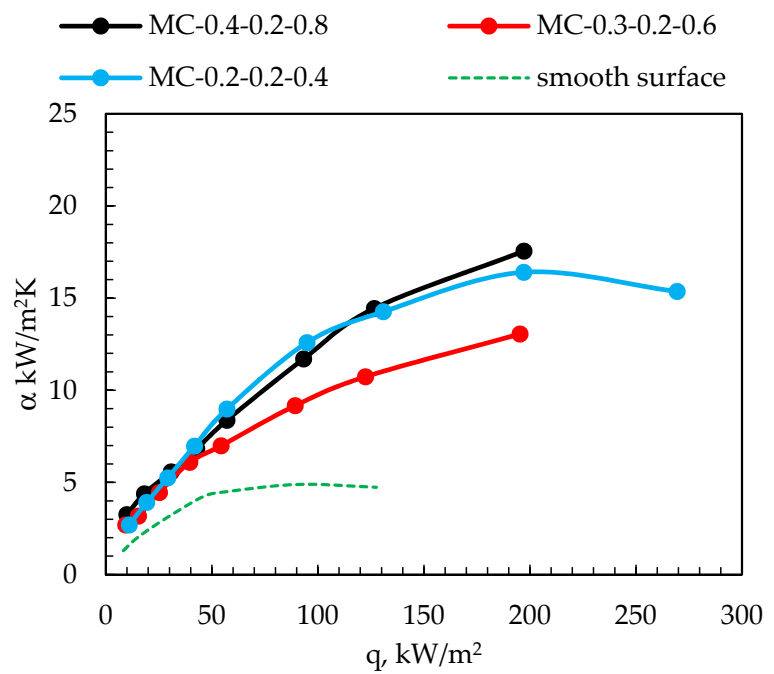

(d)

Figure 7. Boiling curves for FC-72: heat transfer coefficient vs. heat flux: (a) microchannel depth $0.5 \mathrm{~mm}$, (b) microchannel depth $0.4 \mathrm{~mm}$, (c) microchannel depth $0.3 \mathrm{~mm}$, and (d) microchannel depth $0.2 \mathrm{~mm}$.

Figure 7 shows the effect of the width of the microchannel on the heat transfer coefficient at a fixed depth of the microchannel. For deeper microchannels $(\mathrm{h}=0.4 \mathrm{~mm}$ and $\mathrm{h}=0.5 \mathrm{~mm}$ ), at $\mathrm{q}=90-160 \mathrm{~kW} / \mathrm{m}^{2}$, the HTC was found to increase with a decrease in the width of the microchannel. The greatest benefits of using the narrowest microchannels were observed for microchannels with a depth of $0.4 \mathrm{~mm}$. It was found that for $0.2 \mathrm{~mm}$ wide microchannels (MC-0.2-0.4-0.4), the HTC values at heat flux $200 \mathrm{~kW} / \mathrm{m}^{2}$ were greater by approximately $43 \%$ and $54 \%$ than the HTC values obtained using 0.3 (MC-0.3-0.4-0.6) and 0.4 (MC-0.4-0.4-0.8) $\mathrm{mm}$ wide channels, respectively. This phenomenon can be explained mainly by the increasing capillary pressure with smaller microchannel widths. However, for the remaining microchannel depths, this trend is not so clear and the HTC values were similar.

The depth of the microchannels, corresponding to the height of the microfins limiting the microchannels, also has a significant impact on the heat transfer process, as seen in Figure 8. The increasing depth of the microchannels, with their fixed width of $0.2 \mathrm{~mm}$ for the same heat fluxes, causes an increase of the heat transfer coefficient. The highest HTC value was found for the surface with the deepest microchannels (MC-0.2-0.5-0.4) - a 43\% increase was obtained, compared to the shallowest microchannels (MC-0.2-0.2-0.4) at a 
heat flux of about $200 \mathrm{~kW} / \mathrm{m}^{2}$. For the remaining microchannel widths, the largest HTC was obtained by using the deepest microchannels, but there were no consistent trends in heat transfer coefficient change. A similar influence of channel depth was observed in the studies by Cooke and Kandlikar [17] and Orman et al. [18]. It should also be noted that the heat transfer process is also affected by other parameters, such as the wetting angle $[19,20]$, the surface wettability [21,22], and the roughness [23,24].

The smallest pitch $(\mathrm{p}=0.4 \mathrm{~mm})$ is obtained at the smallest microchannel width $(\mathrm{w}=0.2 \mathrm{~mm})$, resulting in the highest concentration of microchannels and the possibility of obtaining a high density of nucleation centers. Greater channel depth values provide a larger surface area, which also results in increased efficiency $(\eta)$ and effectiveness $(\varepsilon)$ of the microchannels. This promotes better heat transfer from the extended surface to the boiling liquid.

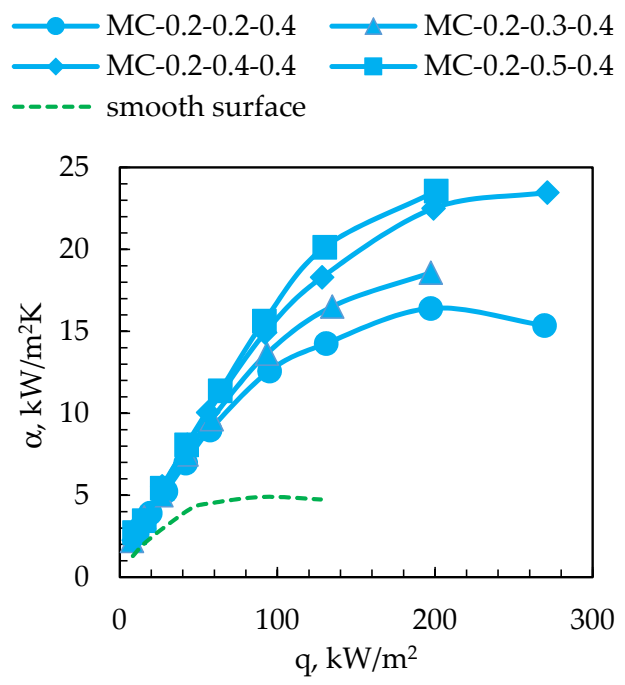

(a)
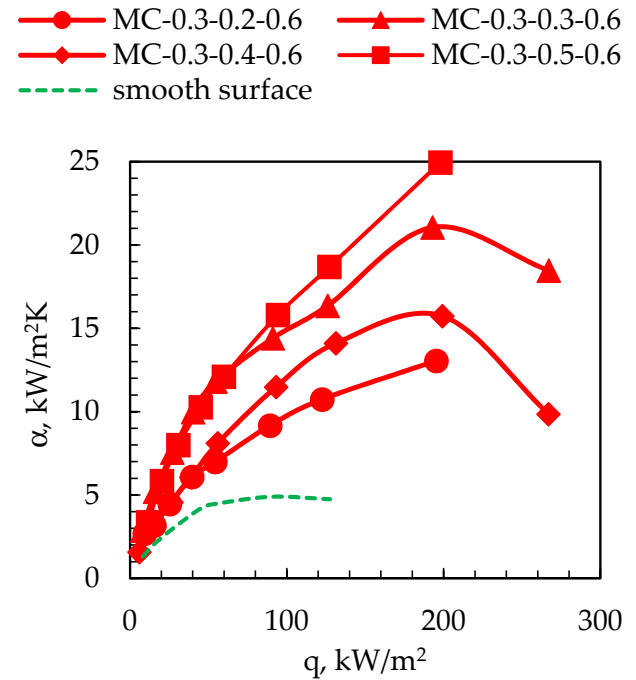

(b)

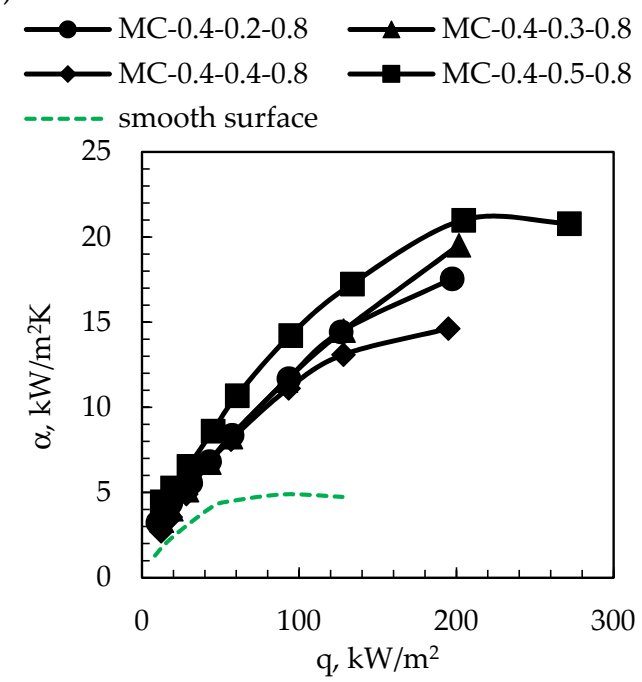

(c)

Figure 8. The influence of the depth of the microchannel on the heat transfer coefficient at fixed microchannel widths: (a) microchannel width $0.2 \mathrm{~mm}$, (b) microchannel width $0.3 \mathrm{~mm}$, and (c) microchannel width $0.4 \mathrm{~mm}$.

Figure 9 shows a comparison from the data of other authors with the authors' own experiment on FC-72. Two surfaces with the largest HTC $\left(25 \mathrm{~kW} / \mathrm{m}^{2} \mathrm{~K}\right.$ for the specimen MC-0.3-0.5-0.6) and the largest CHF $\left(271.7 \mathrm{~kW} / \mathrm{m}^{2}\right.$ for the specimen MC-0.2-0.4-0.4) were compared. The surfaces with $4 \mathrm{~mm}$ high minifins tested by Hao et al. [6], the surfaces with $0.5-4 \mathrm{~mm}$ high minifins analyzed by $\mathrm{Yu}$ and $\mathrm{Lu}[1]$, and the surfaces with copper 
nanowires tested by Kumar et al. [4] were characterized by lower values of heat transfer coefficients. For the surfaces with minifins up to $8 \mathrm{~mm}$ high tested by Rainey and You [25], similar HTCs were obtained as in the case of MC-0.3-0.5-0.6 and MC-0.2-0.4-0.4, but the CHF was lower by $80 \%$ compared to the surface with the highest performance, which was MC-0.2-0.4-0.4. The surface investigated by Hao et al. [6] provided an $8 \%$ lower $\mathrm{CHF}$, but at the same time, the maximum HTC was $88 \%$ lower than that of HTC for the surface MC-0.3-0.5-0.6.

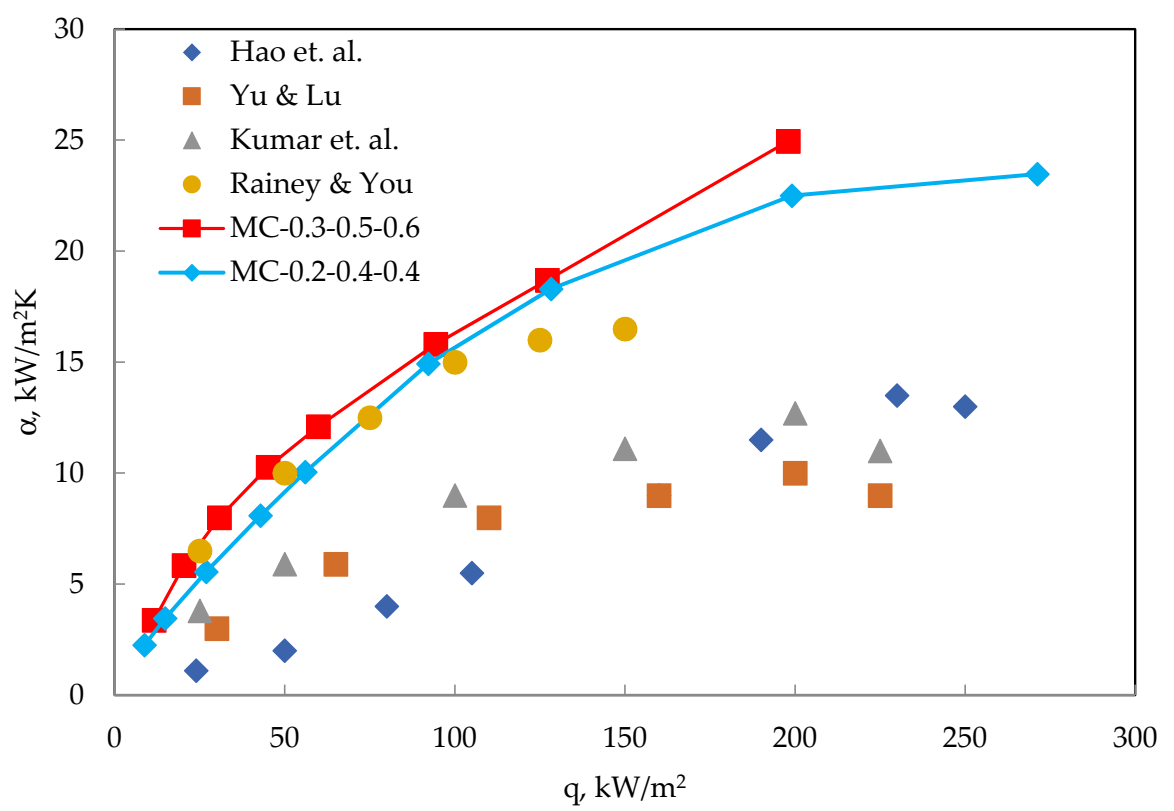

(a)

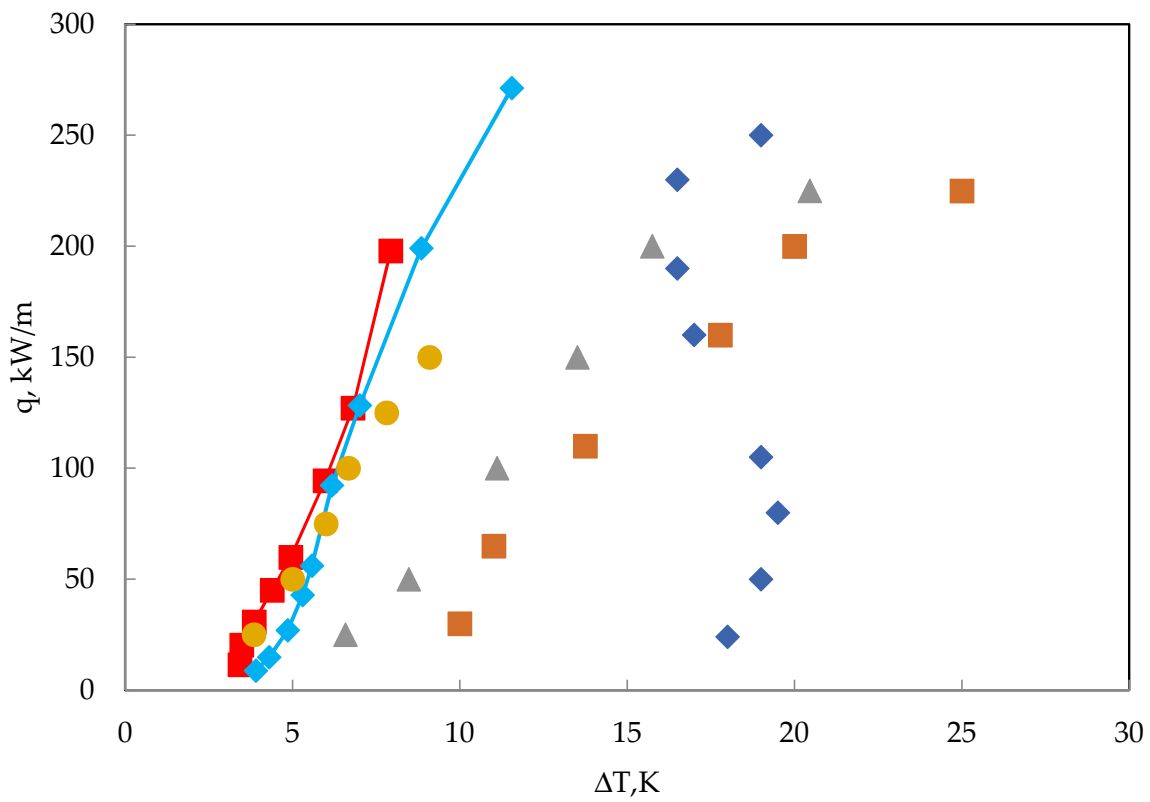

(b)

Figure 9. Comparison of boiling curves of other authors (surfaces with minifins or with nanowires) with experimental data for liquid FC-72 [1,4,6,25]; (a) $\alpha$ vs. q and (b) q vs. $\Delta \mathrm{T}$.

The critical heat flux (CHF) was determined in relation to the performance and efficiency of microfins, as well as the ratio of hydraulic diameter to capillary length. The results are shown in Figure 10a-c. The experimental values were compared with the theoretical dependencies of Kutateladze and Zuber. 


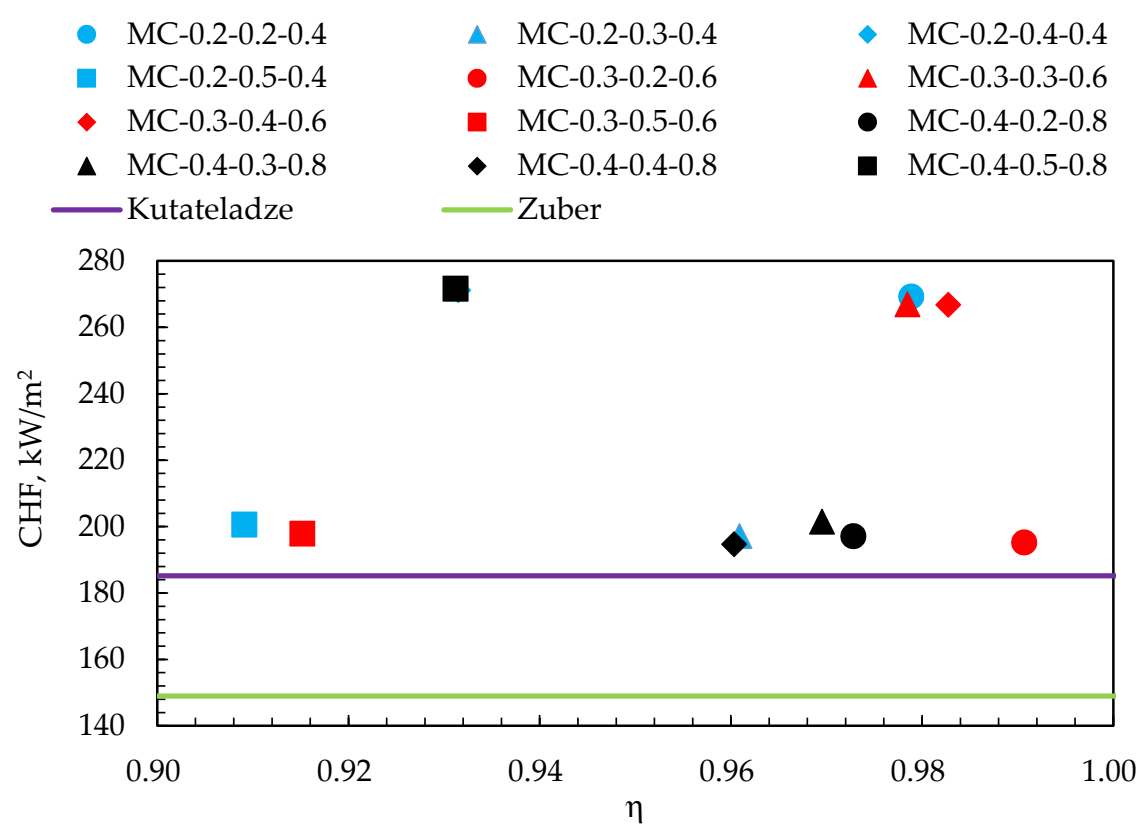

(a)

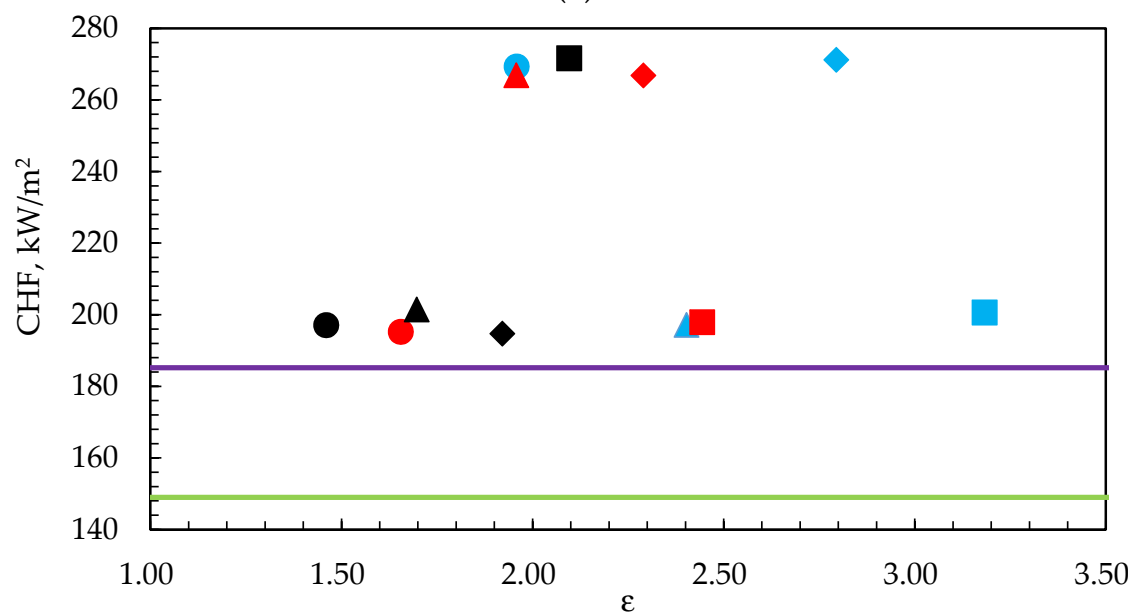

(b)

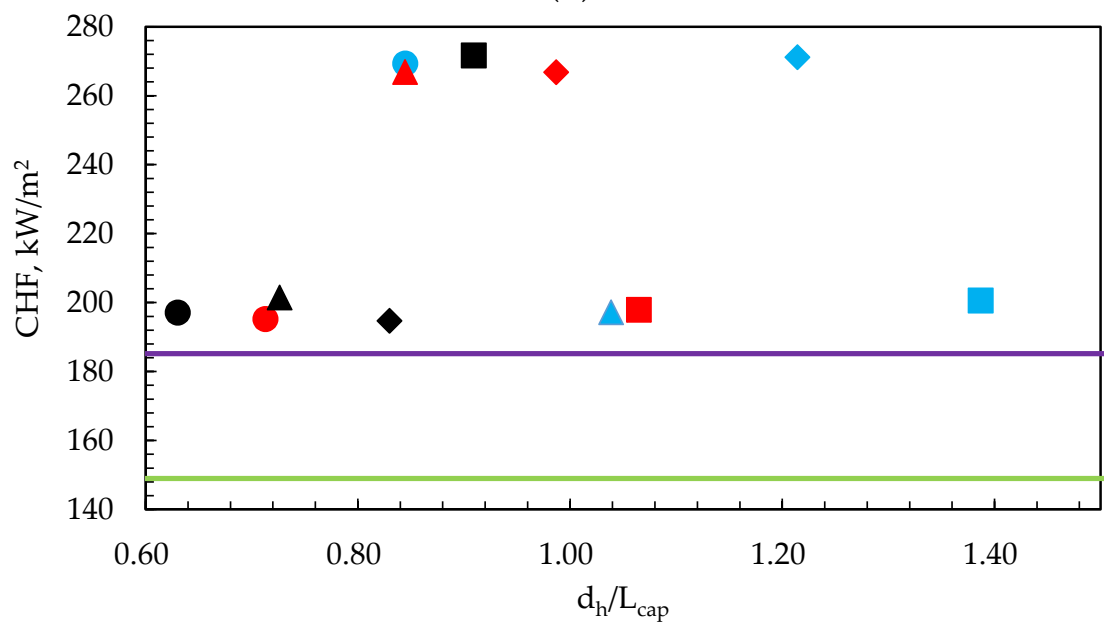

(c)

Figure 10. CHF vs. (a) microfin efficiency, (b) microfin effectiveness, and (c) Bo ${ }^{0.5}$ for FC-72. 
The hydrodynamic instability model of the CHF was proposed by Kutateladze (Equation (11)) and later refined by Zuber (Equation (12)). Kutateladze [26] provided a relationship of the critical heat flux based on the hypothesis that the cause of the change in the mode of boiling was the hydrodynamic instability of the two-phase boundary layer located at the heat transfer surface.

$$
\mathrm{CHF}=0.16 \mathrm{i}_{\mathrm{lv}} \sqrt{\rho_{\mathrm{v}}}\left[\mathrm{g}\left(\rho_{\mathrm{l}}-\rho_{\mathrm{v}}\right) \sigma\right]^{0.25}
$$

Zuber additionally assumed that the boiling of the liquid may take place at a temperature lower than the saturation temperature, i.e., at free convection [27].

$$
\mathrm{CHF}=0.131 i_{\mathrm{lv}} \sqrt{\rho_{\mathrm{v}}}\left[\mathrm{g}\left(\rho_{\mathrm{l}}-\rho_{\mathrm{v}}\right) \sigma\right]^{0.25}\left(\frac{\rho_{\mathrm{l}}}{\rho_{\mathrm{l}}+\rho_{\mathrm{v}}}\right)^{0.5}
$$

During the pool boiling on surfaces with microchannels and microfins, the value of $\mathrm{CHF}$ is mainly influenced by the effectiveness of the microchannel and the Bond number, depending on the hydraulic diameter and capillary length. A similar conclusion can be found in [3]. The space between the microfins can significantly increase the capillary pressure, which promotes liquid replenishment within the microchannel and prevents the heat transfer surface from drying out. The critical heat flux is one of the most important factors that determine the possibility of using a heat exchanger based on the pool boiling phenomenon.

The highest value of CHF, at a level of about $270 \mathrm{~kW} / \mathrm{m}^{2}$, is obtained when $\varepsilon=2$ to 2.3 and $\varepsilon=2.8$ (Figure $10 \mathrm{~b}$ ). For $\varepsilon<2$ and $\varepsilon>3$, the CHF obtained was close to the values from the Kutateladze correlation. This means that the maximum heat flux is obtained for the average surface extension $(\varphi=2-3)$ due to the high efficiency of the microfins analyzed. The models presented in the graphs (Figure 10) relate to a smooth surface. The points represent the experimental values for surfaces with microchannels. Based on these graphs, the possibility of obtaining the highest $\mathrm{CHF}$ values can be predicted. With the exception of the MC-0.2-0.4-0.4 and MC-0.4-0.4-0.8 surfaces, the largest CHF can be obtained with the appropriate width to depth ratio: $0.75 \leq \mathrm{w} / \mathrm{h} \leq 1$, which corresponds to $2 \leq \varepsilon \leq 2.3$.

In Figure 11, the HTC increase is related to the product of $\mathrm{Bo}^{0.5} \varepsilon$. Since the pitch of microchannels and microfins is equal to the double width of the microchannel, taking into account the dependence Equations (6), (9) and (10), an equivalent notation of values on the axis of abscissae in the following form can be used:

$$
\mathrm{Bo}^{0.5} \varepsilon_{\text {HTCmax }}=\frac{\mathrm{d}_{\mathrm{h}}}{\mathrm{L}_{\text {cap }}} \eta_{\text {HTCmax }}\left(\frac{\mathrm{h}}{\mathrm{w}}+1\right)
$$

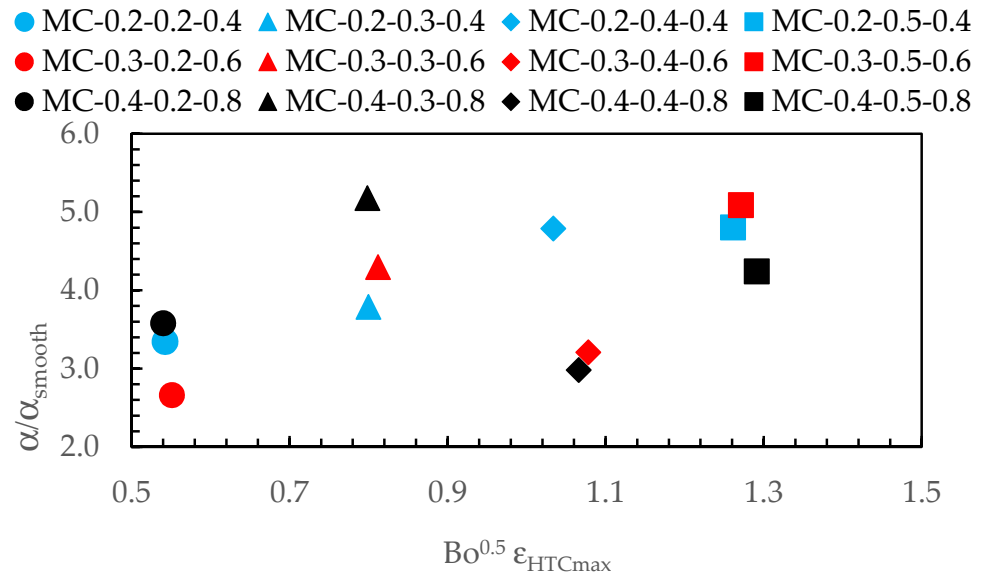

Figure 11. Increase in the heat transfer coefficient at maximum HTC depending on the Bond number and the level of efficiency. 
The dependence transformed in this way allows us to conclude that obtaining high HTC increments is possible by combining the average hydraulic diameters of the microchannel with its large depth, while increasing the hydraulic diameter should result in shallowing the microchannel or reducing the $\mathrm{h} / \mathrm{w}$ ratio.

Figure 12 shows the dependence of the heat transfer coefficient on the geometric parameters of the microchannel. With the smallest microchannel width $(0.2 \mathrm{~mm})$, the largest HTC is obtained for the deepest microchannels $(0.4-0.5 \mathrm{~mm})$. Even with larger widths $(0.3-0.4 \mathrm{~mm})$, it is advantageous to use deep microchannels. In the case of shallower microchannels, nonmonotonic changes occur in the acquisition coefficient as a function of depth, and it is difficult to clearly indicate the best geometry of the tested surface.

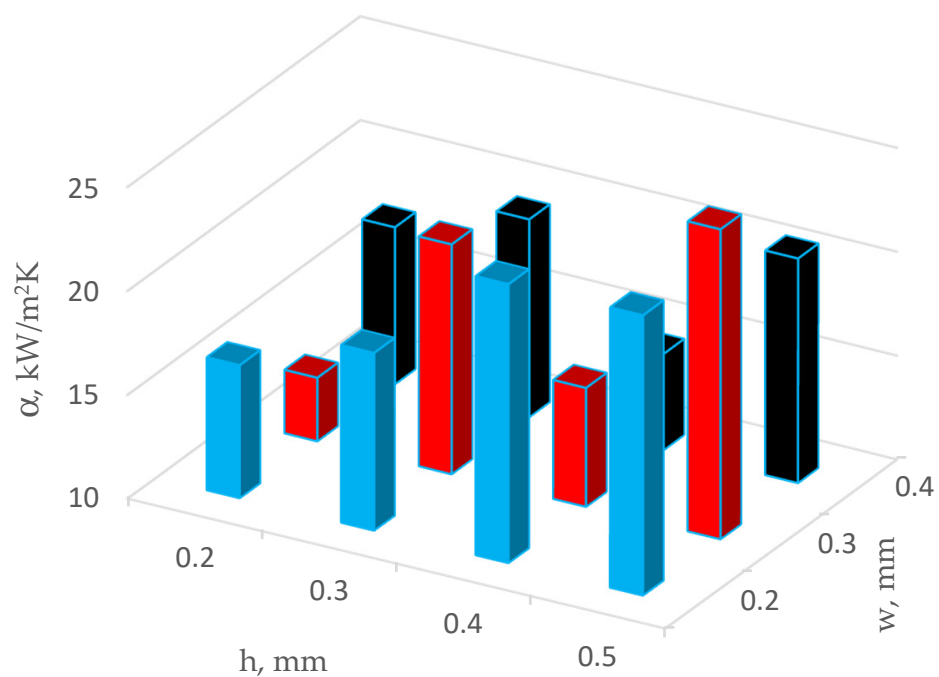

Figure 12. The dependence of HTC on the depth and width of the microchannel.

Of many correlations, the Kutateladze correlation derived from the conditions of similarity is often used for a plain smooth surface [28].

$$
\alpha=0.44 \frac{\lambda_{1}}{\mathrm{~L}_{\text {cap }}} \operatorname{Pr}^{0.35} \operatorname{Re}^{0.7} \mathrm{~K}_{\mathrm{p}}^{0.7}
$$

where the Reynolds number is defined as

$$
\operatorname{Re}=\frac{q L_{\text {cap }}}{\mathrm{i}_{\mathrm{lv}_{\mathrm{v}}} \rho_{\mathrm{v}} v_{1}}
$$

and

$$
\mathrm{K}_{\mathrm{p}}=\frac{\mathrm{p} \cdot 10^{-4} \mathrm{~L}_{\mathrm{cap}}}{\sigma}
$$

Based on the experimental data and the theory of similarity, Kruzhilin [29] proposed the following dependence on the heat transfer coefficient by introducing two additional similarity numbers.

$$
\begin{gathered}
\alpha=0.082 \frac{\lambda_{\mathrm{l}}}{\mathrm{L}_{\text {cap }}} \operatorname{Pr}^{-0.45} \mathrm{~K}_{\mathrm{q}}^{0.7} \mathrm{~K}_{\mathrm{u}}^{0.33} \\
\mathrm{~K}_{\mathrm{q}}=\frac{\mathrm{qi}_{\mathrm{lv}} \rho_{\mathrm{v}}}{\mathrm{gT}_{\mathrm{sat}} \lambda_{\mathrm{l}}\left(\rho_{\mathrm{l}}-\rho_{\mathrm{v}}\right)} \\
\mathrm{K}_{\mathrm{u}}=\frac{\mathrm{T}_{\mathrm{sat}} \mathrm{c}_{\mathrm{p}} \sigma \rho_{\mathrm{l}}}{\mathrm{i}_{\mathrm{lv}}^{2} \rho_{\mathrm{v}}^{2} \mathrm{~L}_{\mathrm{cap}}}
\end{gathered}
$$


$\mathrm{Ku}$ denotes the number of active nucleation sites, and $\mathrm{Kq}=\operatorname{RePr} / \mathrm{Ku}$ [30]. The results of the calculation of the HTCs obtained with the use of relations (14) and (17) are almost identical and in the range of 8 to $130 \mathrm{~kW} / \mathrm{m}^{2}$ (Figure 13).

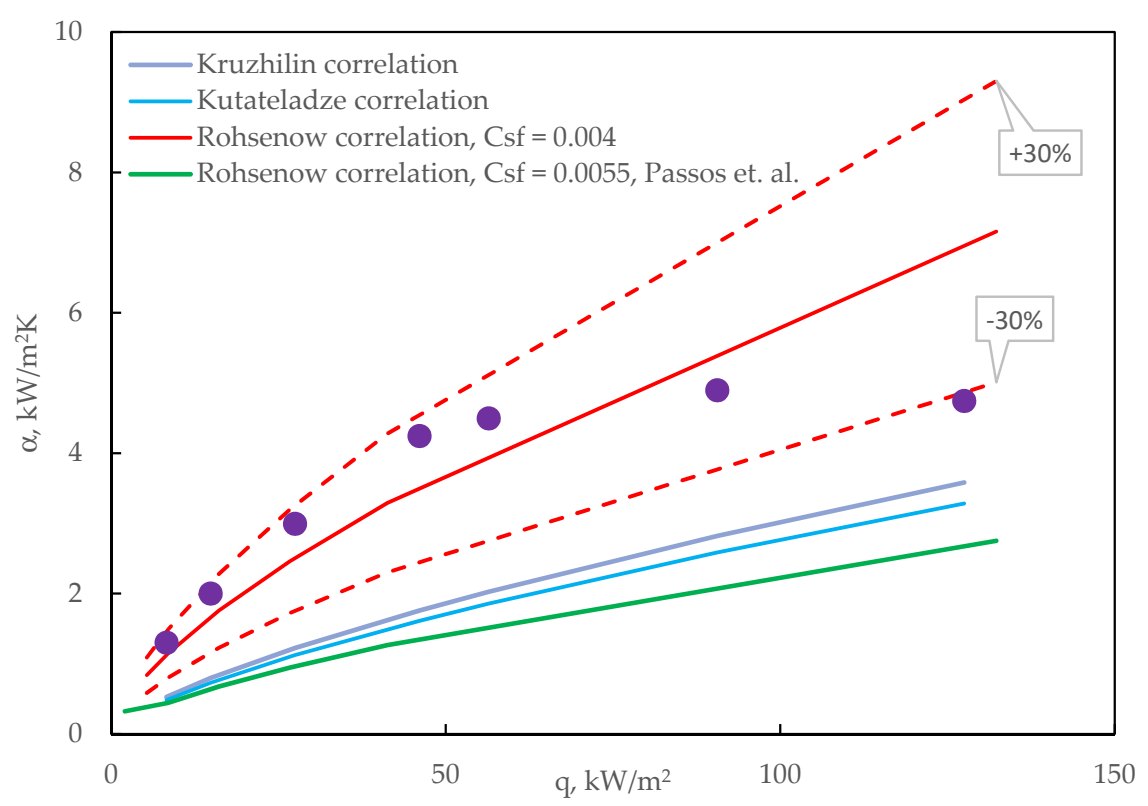

Figure 13. Comparison of the calculated and experimental test results for FC-72, plain surface.

Another correlation widely used in pool boiling is the Rohsenow correlation. The author assumed that the factor that causes the mixing of the liquid and the decisive factor in the heat transfer is the formation, growth, and displacement of vapor bubbles [15]. This dependence can be presented in the form of the following equations:

$$
\begin{gathered}
\frac{\mathrm{c}_{\mathrm{p}} \Delta \mathrm{T}}{\mathrm{i}_{\mathrm{lv}}}=\mathrm{C}_{\mathrm{sf}}\left[\frac{\mathrm{q}}{\mathrm{i}_{\mathrm{lv}} \mu_{\mathrm{l}}} \mathrm{L}_{\mathrm{cap}}\right]^{0.33} \operatorname{Pr}^{1.7} \\
\mathrm{q}=229.859 \Delta \mathrm{T}^{3}
\end{gathered}
$$

The constant $\mathrm{C}_{\mathrm{sf}}$ is selected depending on the type of boiling liquid and the surface. Due to the lack of data for FC-72 boiling on a copper surface with microchannels, the least squares method was used for the determination of this constant with respect to the experimental values.

The regression analysis carried out by the authors allowed for the determination of $\mathrm{C}_{\mathrm{sf}}=0.004$ for FC-72-copper combination for a plain smooth surface. Passos in his study [31] proposed adopting $\mathrm{C}_{\mathrm{sf}}=0.0055$ for a plain copper surface with boiling FC-72. Figure 13 shows the results of the experimental HTCs for the smooth surface with FC-72 and a comparison with the correlations discussed. Based on the graph, it can be concluded that the Rohsenow correlation (Equations (20) and (21)) in the range of $\pm 30 \%$ is the best approximation in relation to the experimental data.

Comparison of the experimental HTC data for microchannels and calculation results according to the Rohsenow correlation (Equations (20) and (21)) shows that the vast majority fall within the range of $\pm 30 \%$ of the error, as seen in Figure 14. The constant $C_{s f}$ in Equation (20) for microchannels was 0.0018 .

The possibility of a simple modification of the Rohsenow correlation was presented, which enables an approximate estimate of the heat transfer coefficients. This is the first attempt to adjust this correlation by changing the constant $C_{\mathrm{sf}}$ to the pool boiling on the microchannel surface. In the future, it is planned to use nonlinear regression to represent the constant and exponents in Equation (20) as a function of the geometric parameters of the microchannels. 


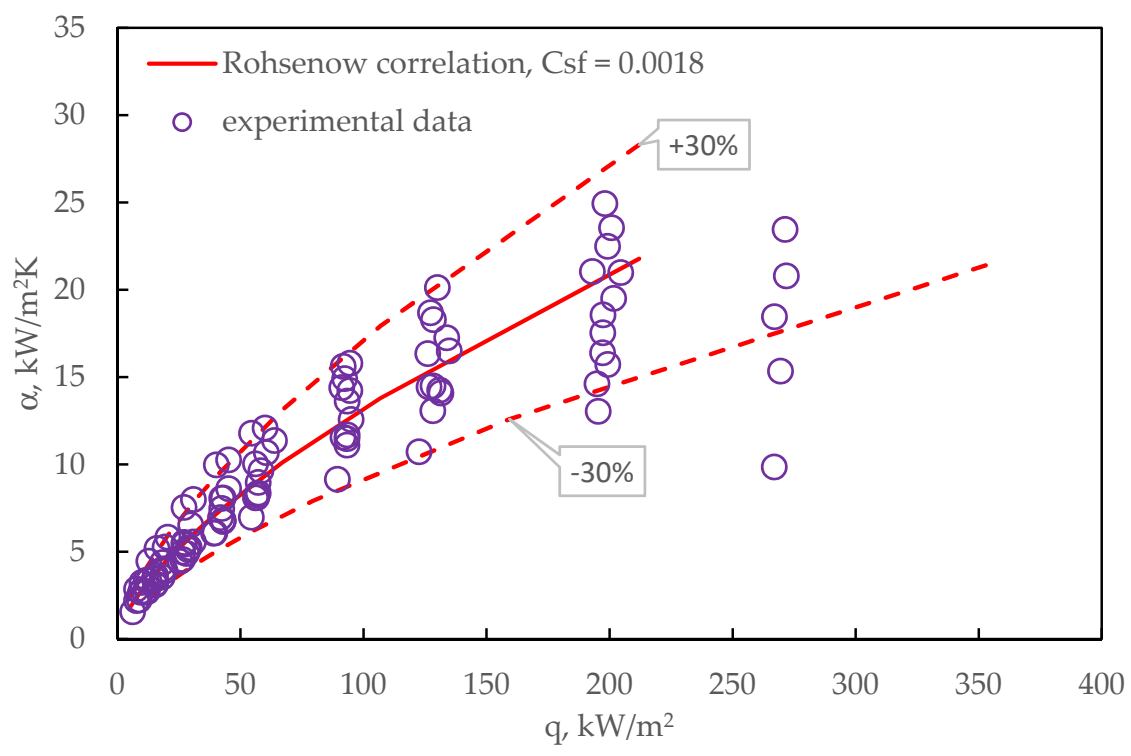

Figure 14. Comparison of the calculated and experimental test results for FC-72 boiling surfaces with microchannels.

\section{Conclusions}

The article presents the results of experimental studies of heat transfer for pool boiling on a plain smooth surface and surfaces covered with microchannels using the FC-72 dielectric liquid. The experiment was performed at atmospheric pressure, within the range from the onset of nucleate boiling to the boiling crisis. The influence of geometrical parameters on the nucleate boiling was analyzed. The results presented in the work allow for the following conclusions to be drawn.

- For the surfaces with microchannels $0.3 \mathrm{~mm}$ wide and $0.5 \mathrm{~mm}$ deep, as well as $0.4 \mathrm{~mm}$ wide and $0.3 \mathrm{~mm}$ deep, the highest increase in the heat transfer coefficient was obtained (about 5.1-fold) in relation to the plain smooth surface.

- The heat transfer coefficients obtained for the tested microchannels reached a level of $25 \mathrm{~kW} / \mathrm{m}^{2} \mathrm{~K}$ and were comparable to HTCs for surfaces with nanotubes.

- The proposed surfaces with microchannels with a width of $0.2-0.4 \mathrm{~mm}$ and a depth of $0.2-0.5 \mathrm{~mm}$ allowed one to obtain a critical heat flux exceeding $270 \mathrm{~kW} / \mathrm{m}^{2}$, which is more than 2.1 times the CHF for the smooth plain surface tested.

- For most of the tested surfaces, the largest CHFs were obtained with the appropriate width to depth ratio: $0.75 \leq \mathrm{w} / \mathrm{h} \leq 1$, which corresponds to the range of the fin effectiveness $2 \leq \varepsilon \leq 2.3$.

- The comparison of the boiling curves showed the impact of the width and depth of the microchannels on the boiling process, but this process is also influenced by other factors, e.g., surface wettability, contact angle, and surface roughness.

- The proposed change of the constant in the Rohsenow correlation made it possible to determine the HTC for the surface with microchannels with an accuracy of $\pm 30 \%$.

Author Contributions: Conceptualization, R.K. and R.P.; methodology, R.K. and R.P.; software, R.K. and R.P.; validation, R.K. and R.P.; formal analysis, R.K. and R.P.; investigation, R.K. and R.P.; resources, R.K. and R.P.; data curation, R.K. and R.P.; writing—original draft preparation, R.K. and R.P.; writing-review and editing, R.K. and R.P.; visualization, R.K. and R.P.; supervision, R.K. and R.P.; project administration, R.K. and R.P.; funding acquisition, R.K. and R.P. All authors have read and agreed to the published version of the manuscript.

Funding: This research received no external funding.

Institutional Review Board Statement: No applicable. 
Informed Consent Statement: Not applicable.

Data Availability Statement: The data presented in this study are available on request from the corresponding author.

Conflicts of Interest: The authors declare no conflict of interest.

\section{Nomenclature}

\begin{tabular}{|c|c|}
\hline A & Area, $\mathrm{m}^{2}$ \\
\hline a & Width of specimen, $\mathrm{m}$ \\
\hline Bo & Bond number \\
\hline$c_{p}$ & Specific heat, $\mathrm{J} \mathrm{kg}^{-1} \mathrm{~K}^{-1}$ \\
\hline $\mathrm{C}_{\mathrm{sf}}$ & Rohsenow constant \\
\hline $\mathrm{CHF}$ & Critical heat flux, $\mathrm{W} \mathrm{m}^{-2}$ \\
\hline d & Diameter, $\mathrm{m}$ \\
\hline $\mathrm{g}$ & Gravitational acceleration, $\mathrm{m} \mathrm{s}^{-2}$ \\
\hline HTC & Heat transfer coefficient, $\mathrm{W} \mathrm{m}{ }^{-2} \mathrm{~K}^{-1}$ \\
\hline h & Microchannel depth, $\mathrm{m}$ \\
\hline i & Enthalpy, $\mathrm{J} \mathrm{kg}^{-1}$ \\
\hline $\mathrm{L}$ & Total length, $\mathrm{m}$ \\
\hline $\mathrm{m}$ & Microfin parameter \\
\hline $\mathrm{p}$ & Pitch, $\mathrm{m}$ \\
\hline $\operatorname{Pr}$ & Prandtl number \\
\hline$q$ & Heat flux, $\mathrm{Wm}^{-2}$ \\
\hline $\operatorname{Re}$ & Reynolds number \\
\hline $\mathrm{T}$ & Temperature, $\mathrm{K}$ \\
\hline $\mathrm{w}$ & Width, $\mathrm{m}$ \\
\hline \multicolumn{2}{|c|}{ Greek letters } \\
\hline$\alpha$ & Heat transfer coefficient, $\mathrm{W} \mathrm{m}{ }^{-2} \mathrm{~K}^{-1}$ \\
\hline$\Delta$ & Error, uncertainty \\
\hline$\Delta \mathrm{T}$ & Superheat referred to the microfin base, $\mathrm{K}$ \\
\hline$\delta$ & Thickness, m \\
\hline$\varepsilon$ & Fin effectiveness \\
\hline$\eta$ & Fin efficiency \\
\hline$\varphi$ & Surface extension coefficient (enhancement factor) \\
\hline$\lambda$ & Thermal conductivity, $\mathrm{W} \mathrm{m}{ }^{-1} \mathrm{~K}^{-1}$ \\
\hline$\mu$ & Dynamic viscocity Pa s \\
\hline$\rho$ & Density, $\mathrm{kg} \mathrm{m}^{-3}$ \\
\hline$\sigma$ & Surface tension, $\mathrm{N} \mathrm{m}^{-1}$ \\
\hline$v$ & Kinematic viscocity $\mathrm{m}^{2} \mathrm{~s}^{-1}$ \\
\hline \multicolumn{2}{|l|}{ Subscripts } \\
\hline bs & Base \\
\hline cap & Capillary \\
\hline $\mathrm{Cu}$ & Copper \\
\hline cyl & Cylinder \\
\hline ext & Extended \\
\hline $\mathrm{h}$ & Hydraulic \\
\hline 1 & Liquid \\
\hline $\mathrm{MC}$ & Microchannel \\
\hline Sn & Tin \\
\hline s & Specimen \\
\hline sat & Saturated \\
\hline $\mathrm{T}$ & Thermocouple \\
\hline $\mathrm{T} 1, \ldots, \mathrm{T} 8$ & Thermocouple number \\
\hline $\mathrm{v}$ & Vapor \\
\hline
\end{tabular}




\section{References}

1. Yu, C.K.; Lu, D.C. Pool Boiling Heat Transfer on Horizontal Rectangular Fin Array in Saturated FC-72. Int. J. Heat Mass Transf. 2007, 50, 3624-3637. [CrossRef]

2. Sajjad, U.; Sadeghianjahromi, A.; Ali, H.M.; Wang, C.-C. Enhanced Pool Boiling of Dielectric and Highly Wetting Liquids-A Review on Surface Engineering. Appl. Therm. Eng. 2021, 195, 117074. [CrossRef]

3. Zhang, Y.; Zhou, J.; Zhou, W.; Qi, B.; Wei, J. CHF Correlation of Boiling in FC-72 with Micro-Pin-Fins for Electronics Cooling. Appl. Therm. Eng. 2018, 138, 494-500. [CrossRef]

4. Kumar, U.; Suresh, S.; Thansekhar, M.R.; Babu, D. Effect of Diameter of Metal Nanowires on Pool Boiling Heat Transfer with FC-72. Appl. Surf. Sci. 2017, 423, 509-520. [CrossRef]

5. Kong, X.; Zhang, Y.; Wei, J. Experimental Study of Pool Boiling Heat Transfer on Novel Bistructured Surfaces Based on Micro-PinFinned Structure. Exp. Therm. Fluid Sci. 2018, 91, 9-19. [CrossRef]

6. Hao, W.; Wang, T.; Jiang, Y.; Guo, C.; Guo, C. Pool Boiling Heat Transfer on Deformable Structures Made of Shape-Memory-Alloys. Int. J. Heat Mass Transf. 2017, 112, 236-247. [CrossRef]

7. Ho, J.Y.; Wong, K.K.; Leong, K.C. Saturated Pool Boiling of FC-72 from Enhanced Surfaces Produced by Selective Laser Melting. Int. J. Heat Mass Transf. 2016, 99, 107-121. [CrossRef]

8. Furberg, R.; Palm, B. Boiling Heat Transfer on a Dendritic and Micro-Porous Surface in R134a and FC-72. Appl. Therm. Eng. 2011, 31, 3595-3603. [CrossRef]

9. Piasecka, M.; Strak, K. Influence of the Surface Enhancement on the Flow Boiling Heat Transfer in a Minichannel. Heat Transf. Eng. 2019, 40, 1162-1175. [CrossRef]

10. Strak, K.; Piasecka, M. The Applicability of Heat Transfer Correlations to Flows in Minichannels and New Correlation for Subcooled Flow Boiling. Int. J. Heat Mass Transf. 2020, 158, 119933. [CrossRef]

11. Piasecka, M.; Strak, K.; Maciejewska, B. Heat Transfer Characteristics during Flow along Horizontal and Vertical Minichannels. Int. J. Multiph. Flow 2021, 137, 103559. [CrossRef]

12. Kaniowski, R.; Pastuszko, R. Boiling of a Refrigerant of Low GWP on the Surface with Copper Microchannels. E3S Web Conf. 2018, 70, 02007. [CrossRef]

13. Pastuszko, R.; Kaniowski, R.; Wójcik, T.M. Comparison of Pool Boiling Performance for Plain Micro-Fins and Micro-Fins with a Porous Layer. Appl. Therm. Eng. 2020, 166, 114658. [CrossRef]

14. Kaniowski, R.; Pastuszko, R.; Nowakowski, Ł. Effect of Geometrical Parameters of Open Microchannel Surfaces on Pool Boiling Heat Transfer. EPJ Web Conf. 2017, 143, 02049. [CrossRef]

15. Rohsenow, W.M.; Hartnett, J.P.; Cho, Y.I. Handbook of Heat Transfer, 3rd ed.; McGraw-Hill Education: New York, NY, USA, 1998; ISBN 978-0-07-053555-8.

16. Kaniowski, R.; Pastuszko, R. Pool Boiling of Water on Surfaces with Open Microchannels. Energies 2021, 14, 3062. [CrossRef]

17. Cooke, D.; Kandlikar, S.G. Effect of Open Microchannel Geometry on Pool Boiling Enhancement. Int. J. Heat Mass Transf. 2012, 55, 1004-1013. [CrossRef]

18. Orman, Ł.J.; Radek, N.; Pietraszek, J.; Szczepaniak, M. Analysis of Enhanced Pool Boiling Heat Transfer on Laser-Textured Surfaces. Energies 2020, 13, 2700. [CrossRef]

19. Kandlikar, S.G. A Theoretical Model to Predict Pool Boiling CHF Incorporating Effects of Contact Angle and Orientation. J. Heat Transf. 2001, 123, 1071-1079. [CrossRef]

20. Liao, L.; Bao, R.; Liu, Z. Compositive Effects of Orientation and Contact Angle on Critical Heat Flux in Pool Boiling of Water. Heat Mass Transf. 2008, 44, 1447-1453. [CrossRef]

21. Lee, J.S.; Lee, J.S. Critical Heat Flux Enhancement of Pool Boiling with Adaptive Fraction Control of Patterned Wettability. Int. J. Heat Mass Transf. 2016, 96, 504-512. [CrossRef]

22. Phan, H.T.; Caney, N.; Marty, P.; Colasson, S.; Gavillet, J. Surface Wettability Control by Nanocoating: The Effects on Pool Boiling Heat Transfer and Nucleation Mechanism. Int. J. Heat Mass Transf. 2009, 52, 5459-5471. [CrossRef]

23. Fan, S.; Jiao, L.; Wang, K.; Duan, F. Pool Boiling Heat Transfer of Saturated Water on Rough Surfaces with the Effect of Roughening Techniques. Int. J. Heat Mass Transf. 2020, 159, 2700. [CrossRef]

24. Kim, J.; Jun, S.; Laksnarain, R.; You, S.M. Effect of Surface Roughness on Pool Boiling Heat Transfer at a Heated Surface Having Moderate Wettability. Int. J. Heat Mass Transf. 2016, 101, 992-1002. [CrossRef]

25. Rainey, K.N.; You, S.M. Pool Boiling Heat Transfer from Plain and Microporous, Square Pin-Finned Surfaces in Saturated FC-72. J. Heat Transf. 2000, 122, 509-516. [CrossRef]

26. Liang, G.; Mudawar, I. Pool Boiling Critical Heat Flux (CHF)—Part 1: Review of Mechanisms, Models, and Correlations. Int. J. Heat Mass Transf. 2018, 117, 1352-1367. [CrossRef]

27. Zuber, N. Nucleate Boiling. The Region of Isolated Bubbles and the Similarity with Natural Convection. Int. J. Heat Mass Transf. 1963, 6, 53-78. [CrossRef]

28. Kutateladze, S.S. Heat Transfer in Condensation and Boiling, 2nd ed.; AEC-tr-3770; Physics and Math: U.S. Atomic Energy Commission, Technical Information Service: Washington, DC, USA, 1959.

29. Pioro, I.L.; Rohsenow, W.; Doerffer, S.S. Nucleate Pool-Boiling Heat Transfer. II: Assessment of Prediction Methods. Int. J. Heat Mass Transf. 2004, 47, 5045-5057. [CrossRef] 
30. Madejski, J. Theory of Heat Transfer; Wydawnictwo Uczelniane Politechniki Szczecińskiej: Szczecin, Poland, 1998. (In Polish)

31. Passos, J.C.; Hirata, F.R.; Possamai, L.F.B.; Balsamo, M.; Misale, M. Confined Boiling of FC72 and FC87 on a Downward Facing Heating Copper Disk. Int. J. Heat Fluid Flow 2004, 25, 313-319. [CrossRef] 